\title{
A Comparative Study of Uses of Ephedrine by Different Doses on Prevention of Hemodynamic Changes Accompanied with Induction of General Anesthesia through Propofol and Fentanyl without Adverse Effects
}

\author{
Ayman Mohamady Eldemrdash, Mohammed Ahmed Mohammed Al-Azhary \\ Department of Anesthesiology, Faculty of Medicine, Aswan University, Aswan, Egypt \\ Email: aymaneldemrdash@yahoo.com
}

How to cite this paper: Eldemrdash, A.M. and Al-Azhary, M.A.M. (2017) A Comparative Study of Uses of Ephedrine by Different Doses on Prevention of Hemodynamic Changes Accompanied with Induction of General Anesthesia through Propofol and Fentanyl without Adverse Effects. Open Journal of Anesthesiology, 7, 341-350. https://doi.org/10.4236/ojanes.2017.710034

Received: September 16, 2017

Accepted: October 28, 2017

Published: October 31, 2017

Copyright $(9) 2017$ by authors and Scientific Research Publishing Inc. This work is licensed under the Creative Commons Attribution International License (CC BY 4.0).

http://creativecommons.org/licenses/by/4.0/

\begin{abstract}
Background: Propofol and fentanyl combination are common with general anesthesia. However, hypotension and bradycardia are common during induction of anesthetic. This study aimed to compare the response of different doses of ephedrine for attenuation of the hemodynamic changes after anesthetic induction without adverse effects. Materials and Methods: This was a randomized, double-blinded, case-controlled clinical trial. One hundred and twenty adult patients were allocated into one of the four groups: receiving IV saline, ephedrine $0.05 \mathrm{mg} / \mathrm{kg}, 0.1 \mathrm{mg} / \mathrm{kg}$, or $0.2 \mathrm{mg} / \mathrm{kg}$ respectively. Induction of anesthesia was done with propofol $3 \mathrm{mg} / \mathrm{kg}$ and fentanyl $1 \mathrm{mg} / \mathrm{kg}$. Alterations in systolic and diastolic blood pressures (SBP, DBP), mean arterial pressure (MAP), and heart rate (HR) were calculated every 1 min after induction, and 2, 3, 4 and $5 \mathrm{~min}$. Then, intubation was made. Results: Baseline hemodynamic variables were comparable between groups. Patients received 0.1 $\mathrm{mg} / \mathrm{kg}$, and $0.2 \mathrm{mg} / \mathrm{kg}$ had less drop in blood pressure both systolic and diastolic, MAP, and HR with no significant rise in side effects. The numbers of patients with hypotension were significantly lower in the group receiving ephedrine $0.2 \mathrm{mg} / \mathrm{kg}$ compared to other groups ( $P$-value 0.05 ). Use of IV ephedrine at a dose of $0.1 \mathrm{mg} / \mathrm{kg}$ was shown to be useful for reduction of hemodynamic changes but did not eliminate the risk of blood pressure drop. Ephedrine $0.2 \mathrm{mg} / \mathrm{kg}$ was better without causing any adverse effects. We can conclude that ephedrine $0.1 \mathrm{mg} / \mathrm{kg}$ was suitable for minimizing or decreasing changes in hemodynamic at propofol-fentanyl induction but ephedrine 0.2 $\mathrm{mg} / \mathrm{kg}$ was better without causing more adverse effects.
\end{abstract}




\section{Keywords}

Propofol, Fentanyl, Hypotension, Ephedrine

\section{Introduction}

Propofol (2.6 diisopropylphenol) is a rapidly acting ideal IV anesthetic drug widely used for induction of general anesthesia [1]. Fentanyl is widespread, commonly used short-acting analgesic agent, frequently used with propofol. The induction of general anesthesia with propofol has, however, been accompanied with a significant drop in the systolic arterial pressure [2]. The mechanism of hypotension caused by propofol is still not well understood. One of the explanations of the hypotensive effects of propofol was the reduction in systemic vascular resistance due to the mixed venous and arterial vasodilatation [3]. Other possible mechanisms may include depression of myocardial contractility and impaired baroreflex [4] [5]. The cardiovascular effects of propofol are obviously increased when combined with fentanyl. Many approaches have been tried to limit this hypotension with unsettled evidence. Fluid preloading with colloid and crystalloid have been administered in various studies to prevent this hypotension, other drugs also used as atropine, glycopyrrolate, ketamine, dopamine, dobutamine but with variable results [1]-[6].

Ephedrine is a non-catecholamine sympathomimetic alkaloid with potent alpha and beta agonist and acts by both direct as well as indirect mechanism. Its cardiovascular effects include the increase in blood pressure, heart rate, contractility, and cardiac output [7]. Ephedrine has been used to limit the hypotensive effects of induction of anesthesia with propofol and fentanyl [5] [6]. Ephedrine is a drug used to maintain blood pressure; mainly by increasing the cardiac output and increasing the heart rate as is it not a potent arterial vasoconstrictor. This may explain why high doses of intravenous ephedrine are accompanied with significant side effects such as reactive hypertension, which is usually considered as systolic BP $>140 \mathrm{mmHg}$ [8].

The purpose of this study was undertaken to compare the response of different doses of ephedrine to determine the most optimal dose of ephedrine for reduction of the hemodynamic changes following anesthetic induction with propofol and fentanyl without causing significant side effects.

\section{Patients and Methods}

After local ethical committee approval and patients informed written consent, one hundred and twenty patients, ASA I or II, were scheduled for elective surgical procedures under GA from May 2017 to September 2017 in Aswan university. Patients with history of any cardiac, respiratory, hepatic, renal, cerebrovascular or endocrinal disease, patients allergic to any medication used in the study, who were taking any drugs affecting heart rate or blood pressure, or those with 
estimated difficult airway, those with morbid obesity $($ BMI $>35)$ and pregnant females were excluded from the study.

Patients were assigned using sealed envelope technique into four groups, no drug or (normal saline) control group (group-A), $0.05 \mathrm{ml} / \mathrm{kg}$ of ephedrine (group-B), $0.1 \mathrm{mg} / \mathrm{kg}$ of ephedrine (group-C) or $0.2 \mathrm{mg} / \mathrm{kg}$ of ephedrine (group-D). The patients received no premedication.

In the anesthetic room, wide bore intravenous access was established. In the operating room, routine monitoring HR, ECG, SPO2, and NIBP were established. Baseline cardiovascular parameters, i.e., heart rate, blood pressure (systolic, diastolic and mean) and oxygen saturation were recorded. Noninvasive blood pressure was measured. Patients received normal saline, ephedrine 0.05, $0.1,0.2 \mathrm{mg} / \mathrm{kg}$ just $1 \mathrm{~min}$ before induction diluted in $10 \mathrm{cc}$ normal saline by another person. Anesthesia was induced with fentanyl $1-2 \mu \mathrm{g} / \mathrm{kg}$ followed by propofol 2 - $3 \mathrm{mg} / \mathrm{kg}$ injected over $30 \mathrm{sec}$. Patients were given atracurium besylate $0.5 \mathrm{mg} / \mathrm{kg}$ as a muscle relaxant. We calculated the hemodynamic variable (arterial blood pressure, heart rate and oxygen saturation) every minute, starting 1 min after induction 2, 3, 4, 5 min (till 5 min after injection of propofol). In this period, bag and mask ventilation were used to maintain SPO2 $>95 \%$, and no endotracheal intubation was done.

After the study period, patients were intubated, and anesthesia was continued as required. Hypotension (SBP $<20 \%$ of baseline) was treated with rapid infusions of ringers lactate $15-20 \mathrm{ml} / \mathrm{min}$.

The statistical analysis of qualitative data was done by using Chi-square test. The quantitative data were analyzed by using one-way ANOVA test. A $P$-value less than 0.05 was considered statistically significant. Quantitative data were presented as mean $( \pm S D)$ while qualitative data were presented as numbers and percentages. Statistical analysis was performed using SPSS version 16.

\section{Results}

Between May 2017 and September 2017, patients scheduled for surgeries under general anesthesia at Aswan University hospitals were invited to participate in our trial. Six patients were excluded from this study, 2 patients have not meeting inclusion criteria, 1 patient declined to participate and 3 patients for other reasons refused to participate, and 120 patients were randomized after informed written consent. In total, 30 patients were randomized to each group. All patients received the intended treatment, completed the study protocol, and were included in the analysis (Figure 1). 120 patients were recruited to the study.

Patients in each group were comparable about age, body weight, and baseline hemodynamic variables; with nonsignificant differences (Table 1).

SBP decreased in all groups after the induction of anesthesia. The drop in SBP was similar in group-A and group-B. In group-A, SBP reduced to $96.3 \pm 6.5$ at 5 $\mathrm{min}$, in group-B, SBP reduced to $97.22 \pm 8.73 \mathrm{mmHg}$, and in group- $\mathrm{C}$, SBP reduced to $103.72 \pm 5.44 \mathrm{mmHg}$, and in group-D, SBP reduced to113.72 \pm 4.44 


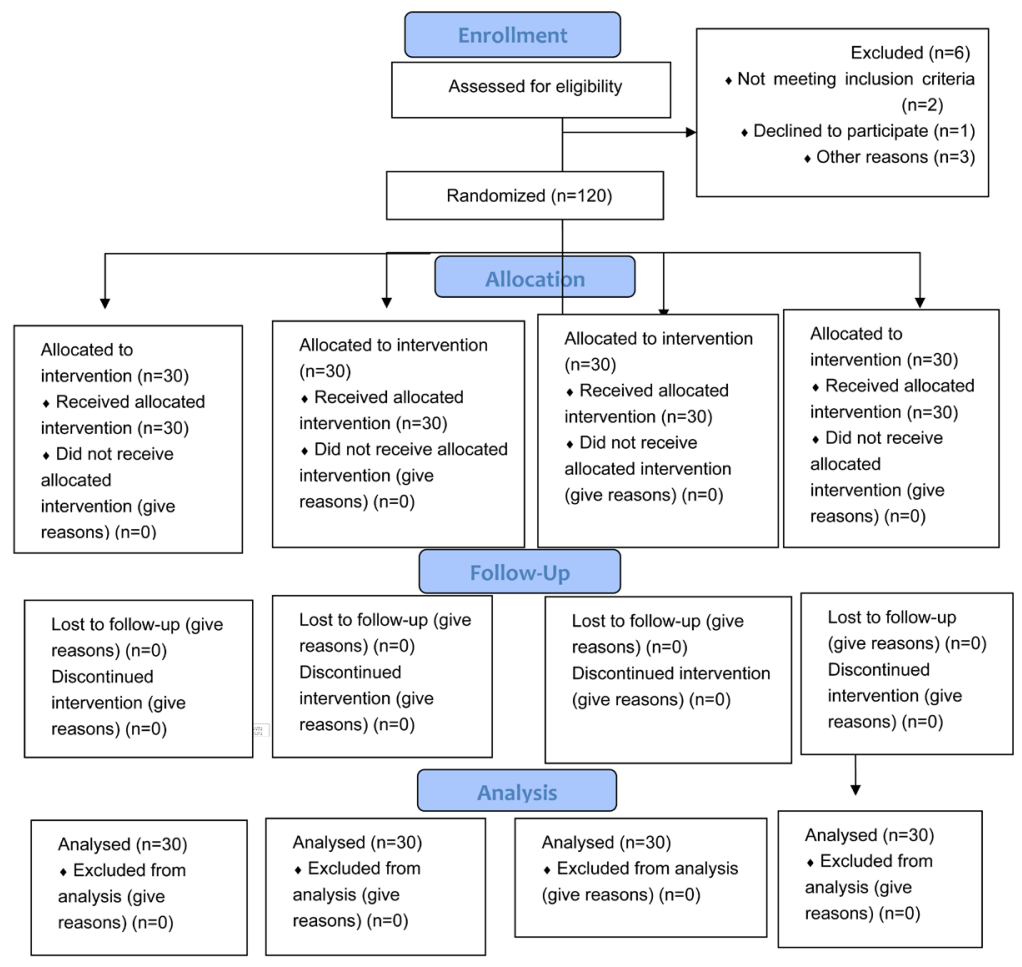

Figure 1. Consort flow diagram.

Table 1. Demographic data and baseline hemodynamic parameters.

\begin{tabular}{cccccc}
\hline & Group-A & Group-B & Group-C & Group-D & P-value \\
& $\mathrm{N}=30$ & $\mathrm{~N}=30$ & $\mathrm{~N}=30$ & $\mathrm{~N}=30$ & \\
\hline Age (year) & $38.47 \pm 10.84$ & $39.77 \pm 9.61$ & $39.76 \pm 10.25$ & $39.77 \pm 11.25$ & 0.80 \\
ASA status: & & & & & \\
I & $27(90 \%)$ & $26(86.7 \%)$ & $28(93.3 \%)$ & $27(90 \%)$ & 0.86 \\
II & $3(10 \%)$ & $4(13.3 \%)$ & $2(6.7)$ & $3(10 \%)$ & \\
Sex: & & & & & \\
Female & $13(43.3 \%)$ & $14(46.7 \%)$ & $12(40 \%)$ & $14(46.7 \%)$ & 0.95 \\
Male & $17(56.7 \%)$ & $16(53.3 \%)$ & $18(60 \%)$ & $16(53.3 \%)$ & \\
Weight (kg) & $62.18 \pm 8.12$ & $64.08 \pm 6.67$ & $62.80 \pm 7.87$ & $62.80 \pm 7.87$ & 0.13 \\
SBP (mm. Hg) & $127.36 \pm 5.13$ & $125.08 \pm 8.51$ & $124.30 \pm 8.58$ & $125.30 \pm 8.58$ & 0.15 \\
DBP (mm. Hg) & $78.68 \pm 5.98$ & $76.98 \pm 7.06$ & $77.46 \pm 7.84$ & $78.46 \pm 7.74$ & 0.13 \\
MAP (mm. Hg) & $94.18 \pm 3.74$ & $93.14 \pm 7.26$ & $93.86 \pm 7.95$ & $92.86 \pm 7.85$ & 0.11 \\
HR (b./min) & $88.06 \pm 9.69$ & $89.26 \pm 12.30$ & $87.70 \pm 12.42$ & $85.70 \pm 12.42$ & 0.33 \\
\hline
\end{tabular}

Data are presented as mean $\pm \mathrm{Sd} .{ }^{*} P$-value $<0.05$.

mmHg. The decrease in SBP was highest in group-A and the lowest in group-D as illustrated in Table 2 and Figure 2.

Diastolic blood pressure (DBP) decreased in all groups after the induction of anesthesia. The decrease in DBP was similar in group-A and group-B and more than group- $C$ and group-D. There was no statistically significant difference in $\mathrm{DBP}$ between group- $\mathrm{A}$ and group- $\mathrm{B}$. In group-A, DBP reduced to $53.30 \pm 4.37$ at $5 \mathrm{~min}$, in group-B DBP reduced to $52.48 \pm 8.05 \mathrm{mmHg}$ and in group- $\mathrm{C}$ diastolic blood pressure reduced to $57.66 \pm 5.32 \mathrm{mmHg}$ and in group-D diastolic blood 


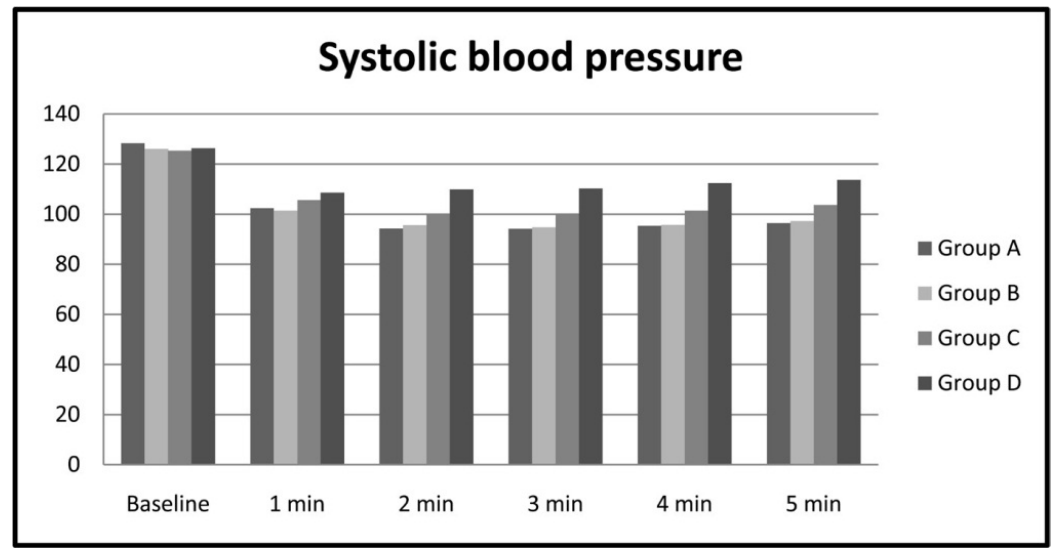

Figure 2. Comparison of SBP during the study period.

Table 2. Comparison of SBP during the study period.

\begin{tabular}{cccccc}
\hline Time & Group-A & Group-B & Group-C & Group-D & $P$-value \\
\hline Baseline & $128.36 \pm 5.13$ & $126.08 \pm 8.51$ & $125.30 \pm 8.58$ & $126.30 \pm 8.58$ & 0.15 \\
1 min. & $102.36 \pm 6.10$ & $101.38 \pm 8.91$ & $105.56 \pm 12.76$ & $108.56 \pm 12.76$ & $0.01^{*}$ \\
2 min. & $94.28 \pm 7.67$ & $95.58 \pm 8.72$ & $99.94 \pm 13.39$ & $109.94 \pm 8.39$ & $0.01^{*}$ \\
3 min. & $94.12 \pm 7.60$ & $94.72 \pm 14.26$ & $100.28 \pm 8.30$ & $110.28 \pm 7.30$ & $0.03^{*}$ \\
4 min. & $95.38 \pm 6.87$ & $95.68 \pm 12.65$ & $101.40 \pm 6.31$ & $112.40 \pm 6.31$ & $0.04^{*}$ \\
5 min. & $96.38 \pm 6.55$ & $97.22 \pm 8.73$ & $103.72 \pm 5.44$ & $113.72 \pm 4.44$ & $<0.001$ \\
\hline
\end{tabular}

Data are presented as mean $\pm \mathrm{Sd} .{ }^{*} P$-value $<0.05$.

pressure reduced to $60.66 \pm 6.32 \mathrm{mmHg}$. The decrease in diastolic blood pressure was highest in group- $\mathrm{B}$ and the lowest in group-D as illustrated in Table 3 and Figure 3.

MAP decreased in all the four groups after the induction of anesthesia. The decrease was similar in group- $A$ and group- $B$ and no significant differences in the MAP between group- $A$ and group- $B$. The decrease in the MAP in group- $A$ and group- $\mathrm{B}$ was similar and more than group- $\mathrm{C}$ and group- $\mathrm{D}$. In group- $\mathrm{A}$, MAP decreased to $67.52 \pm 4.92$ (drop 29\% from the baseline) at $5 \mathrm{~min}$, in group-B MAP decreased to $66.78 \pm 7.16 \mathrm{mmHg}$ (drop 30\% from the baseline) and in group-C mean blood pressure decreased to $69.78 \pm 4.75 \mathrm{mmHg}$ (drop $25 \%$ from the baseline) and in group-D mean blood pressure decreased to 72.78 $\pm 5.75 \mathrm{mmHg}$ (drop 16\% from the baseline). The decrease in mean blood pressure was highest in group-A, and the lowest in group-D. The decrease in the MAP in group- $C$ and group-D was significantly less when compared to group-A and group-B as illustrated in Table 4 and Figure 4.

Baseline heart rate (HR) was comparable in the four groups. In group-A and group- $B$, it decreased following anesthetic induction. In group- $C$ and group-D, it increased from baseline following anesthetic induction. In group-A H.R decreased to $72.84 \pm 11.59$ (drop 20\% from the baseline) at $5 \mathrm{~min}$, in group-B H.R 
Table 3. Comparison of DBP during the study period.

\begin{tabular}{cccccc}
\hline Time & Group-A & Group-B & Group-C & Group-D & $P$-value \\
\hline Baseline & $78.69 \pm 5.88$ & $76.98 \pm 7.16$ & $76.46 \pm 7.95$ & $78.46 \pm 7.93$ & 0.13 \\
1 min. & $57.22 \pm 7.97$ & $56.72 \pm 7.03$ & $58.14 \pm 9.82$ & $62.14 \pm 9.82$ & $0.02^{*}$ \\
2 min. & $48.64 \pm 10.40$ & $49.38 \pm 6.54$ & $54.58 \pm 8.33$ & $63.58 \pm 9.33$ & $0.02^{*}$ \\
3 min. & $47.68 \pm 6.07$ & $48.10 \pm 8.52$ & $53.34 \pm 4.30$ & $66.34 \pm 5.30$ & $0.04^{*}$ \\
4 min. & $47.94 \pm 4.38$ & $48.60 \pm 10.69$ & $54.76 \pm 5.40$ & $64.76 \pm 6.40$ & $<0.001^{*}$ \\
5 min. & $53.30 \pm 4.37$ & $52.48 \pm 8.05$ & $57.66 \pm 5.32$ & $60.66 \pm 6.32$ & 0.08 \\
\hline
\end{tabular}

Data are presented as mean $\pm \mathrm{Sd} .{ }^{\star} P$-value $<0.05$.

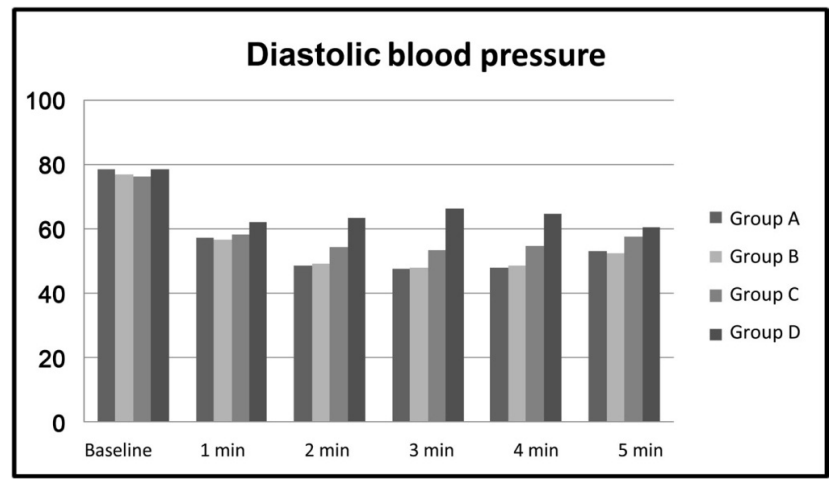

Figure 3. Comparison of DBP during the study period.

Table 4. Comparison of the MAP during the study period.

\begin{tabular}{cccccc}
\hline Time & Group-A & Group-B & Group-C & Group-D & $P$-value \\
\hline Baseline & $94.18 \pm 3.64$ & $93.14 \pm 7.16$ & $93.86 \pm 7.85$ & $93.86 \pm 7.85$ & 0.11 \\
1 min. & $72.36 \pm 6.04$ & $72.98 \pm 6.45$ & $73.8 \pm 10.23$ & $77.80 \pm 11.23$ & $0.01^{*}$ \\
2 min. & $62.56 \pm 7.92$ & $63.88 \pm 7.32$ & $67.74 \pm 9.60$ & $74.74 \pm 10.60$ & $0.02^{*}$ \\
3 min. & $62.86 \pm 4.18$ & $62.70 \pm 9.03$ & $68.92 \pm 4.23$ & $73.92 \pm 6.23$ & $0.04^{*}$ \\
4 min. & $63.64 \pm 4.43$ & $64.24 \pm 10.89$ & $69.62 \pm 4.11$ & $76.62 \pm 4.11$ & $0.02^{*}$ \\
5 min. & $67.52 \pm 4.92$ & $66.78 \pm 7.16$ & $69.78 \pm 4.75$ & $79.78 \pm 5.75$ & $0.01^{*}$
\end{tabular}

Data are presented as mean $\pm \mathrm{Sd} .{ }^{\star} P$-value $<0.05$.

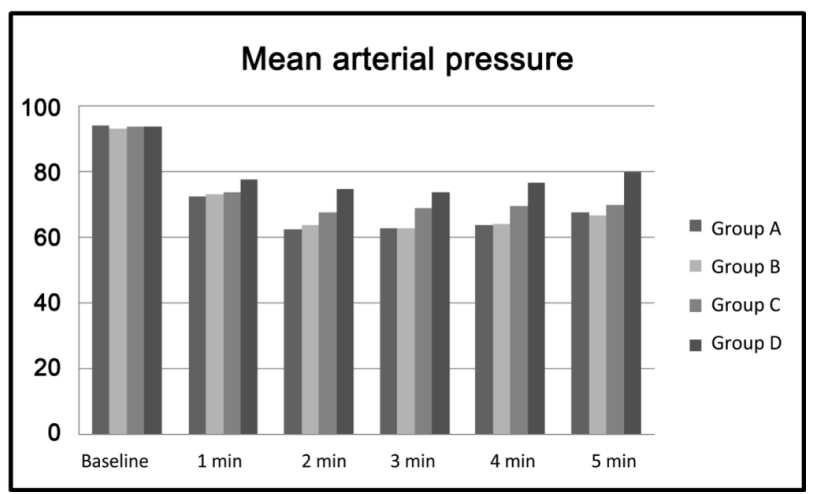

Figure 4. Comparison of the MAP during the study period. 
decreased to $78.88 \pm 11.71$ (drop $11 \%$ from the baseline) and in group-C H.R increased to $88.46 \pm 8.67$ (increase $2 \%$ from the baseline) and in group-D H.R increased to $90.66 \pm 7.57$ (increase $5 \%$ from the baseline). The decrease in H.R was in group-A $20 \%$ and group-B $11 \%$ and increase in group-C $2 \%$ and group-D $5 \%$ was insignificantly in all groups as illustrated in Table 5 and Figure 5.

The incidence of hypotension in the four groups during the study period was also compared. The number of patients developing hypotension at 1 min was not significant when compared to the four groups $(P>0.05)$. The incidence of hypotension was significant at $2 \mathrm{~min}, 3 \mathrm{~min}, 4 \mathrm{~min}$ and $5 \mathrm{~min}(P<0.05)$. The incidence of hypotension was highest in group-A followed by group-B and group-C and group-D as illustrated in Table 6 and Figure 6.

Table 5. Comparison of HR during the study period.

\begin{tabular}{cccccc}
\hline Time & Group-A & Group-B & Group-C & Group-D & $P$-value \\
\hline Baseline & $89.16 \pm 9.59$ & $87.26 \pm 13.32$ & $86.70 \pm 11.40$ & $85.70 \pm 12.40$ & 0.33 \\
1 min. & $90.46 \pm 12.58$ & $89.72 \pm 16.98$ & $87.16 \pm 9.91$ & $88.26 \pm 9.91$ & 0.48 \\
2 min. & $78.38 \pm 11.94$ & $79.58 \pm 13.68$ & $89.74 \pm 7.29$ & $90.74 \pm 6.29$ & $<0.001^{\star}$ \\
3 min. & $76.98 \pm 13.92$ & $79.88 \pm 13.25$ & $85.06 \pm 7.36$ & $87.26 \pm 8.36$ & $<0.001^{\star}$ \\
4 min. & $73.92 \pm 12.29$ & $77.26 \pm 11.42$ & $86.48 \pm 7.55$ & $88.58 \pm 7.65$ & $<0.001^{\star}$ \\
5 min. & $72.84 \pm 11.59$ & $78.88 \pm 11.71$ & $88.46 \pm 8.67$ & $90.66 \pm 7.57$ & $<0.001^{\star}$ \\
\hline
\end{tabular}

Data are presented as mean $\pm \mathrm{Sd} .{ }^{*} P$-value $<0.05$.

Table 6. The number of patients developing hypotension and time of onset of hypotension.

\begin{tabular}{cccccc}
\hline Time & Group-A & Group-B & Group-C & Group-D & $P$-value \\
\hline 1 min. & $7(23 \%)$ & $6(20 \%)$ & $6(20 \%)$ & $4(15 \%)$ & 0.13 \\
2 min. & $26(85 \%)$ & $19(62 \%)$ & $12(40 \%)$ & $9(30)$ & $0.05^{*}$ \\
3 min. & $26(85 \%)$ & $19(62 \%)$ & $13(42 \%)$ & $7(25 \%)$ & $0.05^{*}$ \\
4 min. & $24(80 \%)$ & $20(65 \%)$ & $11(36 \%)$ & $6(20 \%)$ & $0.05^{*}$ \\
5 min. & $22(75 \%)$ & $6(20 \%)$ & $16(54 \%)$ & $22(75 \%)$ & $0.05^{*}$ \\
\hline
\end{tabular}

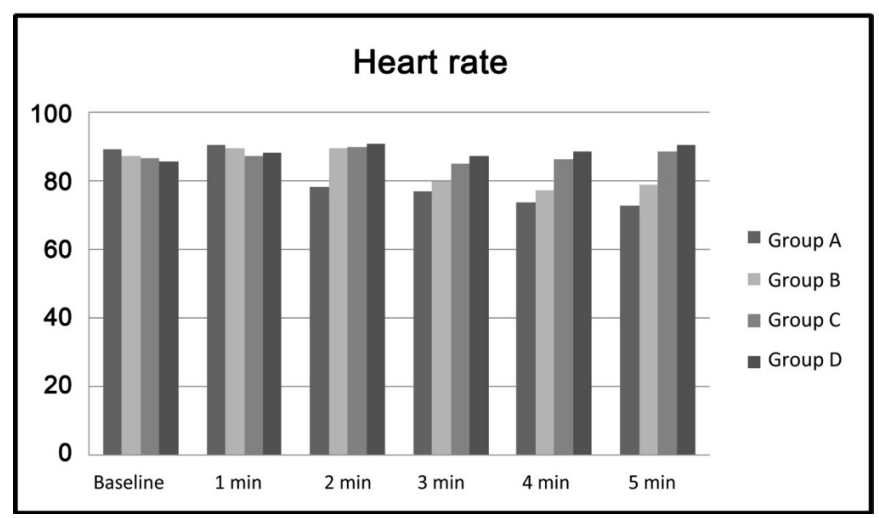

Figure 5. Comparison of HR during the study period. 


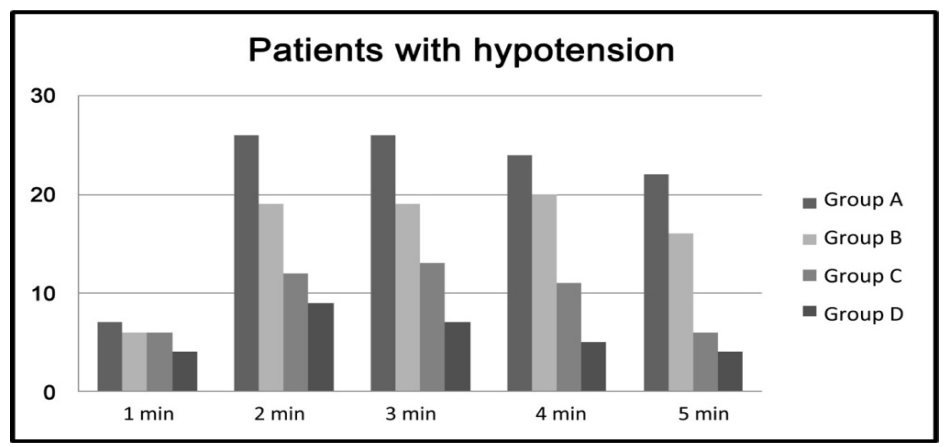

Figure 6. The number of patients developing hypotension and time of onset on hypotension.

\section{Discussion}

Hypotension after induction with propofol is well known [9]. The cause of this hypotension has been found to be a depression of myocardial contractility and a reduced systemic vascular resistance [10]. Fentanyl was used for adjuvant induction of anesthesia with propofol. Fentanyl in small doses has minimal cardiovascular effects [11]. However, when used with propofol for induction of anesthesia, it may heighten the bradycardia and hypotensive effects of propofol [12].

This study confirms that induction of anesthesia with propofol combined with fentanyl in ASA-I and II patients is usually accompanied with significant systemic arterial hypotension. Preinduction IV injection of ephedrine in a dose of $0.1 \mathrm{mg} / \mathrm{kg}$ significantly minimized, but did not eliminate the decrease of BP, but the dose of $0.2 \mathrm{mg} / \mathrm{kg}$ was much better, where the drop in SBP from base line after 5 minute was $25 \%$ and $22 \%$ in group-A and group-B but $16 \%$ in group-C and only $11 \%$ drop in group-D. Also significant decrease in systolic blood pressure from the baseline was observed in all the groups after propofol administration in our study dropped $21 \%, 20 \%, 16 \%, 10 \%$ from the base line respectively A-, B-, C-, D-groups after $1 \mathrm{~min}$. Gamlin et al. [13] found that 15 or $20 \mathrm{mg}$ of ephedrine premixed with $20 \mathrm{ml}$ of $1 \%$ propofol maintained blood pressure at preinduction values, whereas ephedrine $10 \mathrm{mg}$ was insufficient. The difference in observations could be connected with a higher dose of ephedrine $(15,20$ and $25 \mathrm{mg}$ ) in other studies than in ours $(0.2 \mathrm{mg} / \mathrm{kg}$, with a mean dose of $10 \mathrm{mg})$.

In this study, we observed that prophylactic IV dose of ephedrine was effective in limiting the hypotension during propofol induction in doses $0.1 \mathrm{mg} / \mathrm{kg}$ and $0.2 \mathrm{mg} / \mathrm{kg}$. But ephedrine did not eliminate the reduction in BP associated with induction of anesthesia with propofol and fentanyl. Our results are comparable to those of Michelsen et al. [14]. They found that prophylactic IV ephedrine 0.2 $\mathrm{mg} / \mathrm{kg}$ significantly weakened, but did not eliminate the reduction in blood pressure during propofol and fentanyl induction. Similarly, El-Beheiry et al. [15] observed that $0.07 \mathrm{mg} / \mathrm{kg}$ ephedrine taken just before induction of anesthesia by propofol and eventually tracheal intubation maintained blood pressure at pre-induction levels for up to $6 \mathrm{~min}$ after induction. The cause that a smaller dose of ephedrine is effective (by effect of intubation) depends on the sympa- 
thoadrenal-stimulating. Though pre-induction by ephedrine attenuated the hypotensive effects of propofol, some patients still worldly-wised in a reduction in BP to $<80 \%$ of baseline. The cause for this may be that ephedrine mainly keeps the arterial blood pressure by increasing the cardiac output [16], whereas propofol, under conditions similar to those in the present study, causes arterial hypotension by reducing peripheral vascular resistance [2] [17]. Gopalakrishnan and colleagues [18] have reported ephedrine to be ineffective in preventing hypotension after induction of anesthesia with propofol and rocuronium during rapid tracheal intubation. However, Gamlin et al. [19] had reported full effectiveness in obtunding hypotensive effects of propofol when ephedrine was mixed with propofol. But marked tachycardia was observed in the majority of patients in their study. In our study, we observed a decrease in heart rate in control group and increased in the ephedrine group, but it was less than $20 \%$ of the baseline and statistically insignificant. Gamlin et al. [20] reported marked tachycardia associated with the use of ephedrine in combination with propofol in the majority of patients. The difference in observations could be correlated with higher doses of ephedrine (20 and $25 \mathrm{mg}$ ) in other studies than in ours $(0.2$ $\mathrm{mg} / \mathrm{kg}$ ). Dhungana et al. [18] also reported insignificant increases in heart rate in patients receiving ephedrine. In conclusion, we found that the prophylactic intravenous injection of ephedrine $0.1 \mathrm{mg} / \mathrm{kg}$ significantly attenuated, but did not abolish the reduction in systolic blood pressure associated with induction of anesthesia with propofol and fentanyl, but $0.2 \mathrm{mg} / \mathrm{kg}$ was much better without causing any adverse effects. We recommended that ephedrine reduced the incidence of hypotension in a significant number of our ASA I and II grade patients, and their safety and efficacy needed to be used during routine clinical practice and in high-risk groups and critically ill patients, especially ephedrine $0.2 \mathrm{mg} / \mathrm{kg}$.

\section{References}

[1] Smith, I., White, P.F., Nathanson, M., et al. (1994) Propofol: An Update on Its Clinical Use. Anesthesiology, 81, 1005-1043. https://doi.org/10.1097/00000542-199410000-00028

[2] Fairfield, J.E., Dritsas, A. and Beale, R.J. (1991) Hemodynamic Effects of Propofol: Induction with $2.5 \mathrm{mg} / \mathrm{kg}^{-1}$. British Journal of Anesthesia, 67, 618-620. https://doi.org/10.1093/bja/67.5.618

[3] Muzi, M., Berens, R.A., Kampine, J.P. and Ebert, T.J. (1992) Venodilation Contributes to Propofol-Mediated Hypotension in Humans. Anesthesia and Analgesia, 74, 877-883. https://doi.org/10.1213/00000539-199206000-00017

[4] Robinson, B.J., Ebert, T.J., O’Brien, T.J., Colinco, M.D. and Muzi, M. (1997) Mechanisms Whereby Propofol Mediates Peripheral Vasodilation in Humans: Sympathoinhibition or Direct Vascular Relaxation? Anesthesiology, 86, 64-72. https://doi.org/10.1097/00000542-199701000-00010

[5] Cullen, P.M., Turtle, M., Prys-Roberts, C., Way, W.L. and Dye, J. (1987) Effect of Propofol Anesthesia on Baroreflex Activity in Humans. Anesthesia and Analgesia, 66, 1115-1120.

[6] Ozkocak, I., Altunkaya, H., Ozer, Y., Ayoolu, H., Demirel, C.B. and Cicek, E. (2005) 
Comparison of Ephedrine and Ketamine in Prevention of Injection Pain and Hypotension due to Propofol Induction. European Journal of Anesthesiology, 22, 44-48. https://doi.org/10.1097/00003643-200501000-00010

[7] Ralston, D.H., Shnider, S.M. and DeLorimier, A.A. (1974) Effects of Equipotent Ephedrine, Metaraminol, Mephentermine, and Methoxamine on Uterine Blood Flow in the Pregnant Ewe. Anesthesiology, 40, 354-370.

https://doi.org/10.1097/00000542-197404000-00009

[8] Vercauteren, M.P., Coppejans, H.C., Hoffmann, V.H., Mertens, E. and Adriaensen, H.A. (2000) Prevention of Hypotension by a Single 5-Mg Dose of Ephedrine during Small-Dose Spinal Anesthesia in Prehydrated Cesarean Delivery Patients. Anesthesia and Analgesia, 90, 324-327.

[9] Skues, M.A., Richards, M.J., Jarvis, A.P. and Prys-Roberts, C. (1989) Preinduction Atropine or Glycopyrrolate and Hemodynamic Changes Associated with Induction and Maintenance of Anesthesia with Propofol and Alfentanil. Anesthesia and Analgesia, 69, 386-390. https://doi.org/10.1213/00000539-198909000-00020

[10] Kasaba, T., Yamaga, M., Iwasaki, T., Yoshimura, Y. and Takasaki, M. (2000) Ephedrine, Dopamine, or Dobutamine to Treat Hypotension with Propofol during Epidural Anesthesia. Canadian Journal of Anesthesia, 47, 237-241. https://doi.org/10.1007/BF03018919

[11] Chiu, C.L., Tew, G.P., and Wang, C.Y. (2001) The Effect of Prophylactic Metaraminol on Systemic Hypotension Caused by Induction of Anesthesia with Propofol in Patients over 55 Years Old. Anaesthesia, 56, 893-897. https://doi.org/10.1046/j.1365-2044.2001.02059-4.x

[12] Turner, R.J., Gatt, S.P., Kam, P.C.A., Ramzan, I. and Daley, M. (1998) Administration of a Crystalloid Fluid Preload Does Not Prevent the Decrease in Arterial Blood Pressure after Induction of Anesthesia with Propofol and Fentanyl. British Journal of Anesthesia, 80, 737-741. https://doi.org/10.1093/bja/80.6.737

[13] Gamlin, F., Vucevic, M., Winslow, L. and Berridge, J. (1996) The Hemodynamic Effects of Propofol in Combination with Ephedrine. Anaesthesia, 51, 488-491. https://doi.org/10.1111/j.1365-2044.1996.tb07799.x

[14] Michelsen, I., Helbo-Hansen, H.S., Kohler, F., Lorenzen, A.G., Rydlund, E. and Bentzon, M.W. (1998) Prophylactic Ephedrine Attenuates the Hemodynamic Response to Propofol in Elderly Female Patients. Anesthesia and Analgesia, 86, 477-481. https://doi.org/10.1213/00000539-199803000-00004

[15] El-Beheiry, H., Kim, J., Milne, B. and Seegobin, R. (1995) Prophylaxis against the Systemic Hypotension Induced by Propofol during Rapid Sequence Intubation. Canadian Journal of Anesthesia, 42, 875-878. https://doi.org/10.1007/BF03011034

[16] Critchley, L.A.H., Stuart, J.C., Conway, F. and Short, T.G. (1995) Hypotension during Subarachnoid Anesthesia: Hemodynamic Effects of Ephedrine. British Journal of Anesthesia, 74, 373-378. https://doi.org/10.1093/bja/74.4.373

[17] Claeys, M.A., Gepts, E. and Camu, F. (1988) Haemodynamic Changes during Anesthesia Induced and Maintained with Propofol. British Journal of Anesthesia, 60, 3-9. https://doi.org/10.1093/bja/60.1.3

[18] Dhungana, Y., Bhattarai, B.K., Bhadani, U.K., Biswas, B.K. and Tripathi, M. (2008) Prevention of Hypotension during Propofol Induction: A Comparison of Preloading with 3.5\% Polymers of Degraded Gelatin (Haemaccel) and Intravenous Ephedrine. Nepal Medical College Journal, 10, 16-19.

[19] Al-Ghamdi, A. (2004) Hydroxyethylstarch 6\% Preload Does Not Prevent the Hypotension Following Induction with Propofol and Fentanyl. Middle East Journal of 
Anesthesiology, 17, 959-968.

[20] Gamlin, F., Freeman, J., Winslow, L., Berridge, J. and Vucevic, M. (1999) The Hemodynamic Effects of Propofol in Combination with Ephedrine in Elderly Patients (ASA Groups 3 and 4). Anesthesia and Intensive Care, 27, 477-480. 